\title{
The Impact of Radiotherapy and Concomitant Weekly Cisplatin on Treatment Outcome of Locally Advanced Nasopharyngeal Carcinoma
}

\author{
Ali Mohammed Ali ${ }^{a}$ and Ashraf M Elyamany ${ }^{b}$ \\ ${ }^{a}$ Department of Clinical Oncology\&Nuclear Medicine, Sohag University, and ${ }^{b}$ Department of Medical \\ Oncology, South Egypt Cancer Institute, Assuit University, Egypt.
}

\begin{abstract}
Purpose: The results of radiotherapy alone in patients with locally advanced nasopharyngeal carcinoma (NPC) were disappointing. Cisplatin-based concomitant chemoradiotherapy (CCRT) has demonstrated higher rates of local control and significantly reduced distant metastasis than radiotherapy (RT) alone in patients with locally advanced NPC. In view of the high rate of severe mucosal and bone marrow toxicities reported with the high doses of cisplatin and based on many studies that reported on the efficacy of weekly low dose cisplatin given concomitantly with RT, it was a standard in our department to treat such patients with radiochemotherapy utilizing low dose of weekly cisplatin. The aim of this retrospective study is to investigate the efficacy and tolerability of low dose cisplatin CCRT in terms of overall survival (OS), disease free survival (DFS), local control rate (LCR) and, treatment related morbidities.
\end{abstract}

Methods: We revised the registered data in the fiies of patients with nasopharyngeal carcinoma treated in Sohag Cancer Institute and the Department of Clinical Oncology in Sohag University Hospital between August 1999 and November 2012. Thirty two patients with locally advanced, non metastatic, nasopharyngeal carcinoma are found in our research. Twenty five patients were treated with CCRT using low dose of weekly cisplatin were compared with seven patients treated with RT alone.

Results: At the end of treatment, complete response (CR), partial response (PR) and, stable disease (SD) were attained in $68 \%, 20 \%$ and, $8 \%$ with CCRT versus $57 \%, 28.5 \%$ and $14 \%$ with RT alone $(P=0.11)$. During follow up, although the rate of loco regional distant control (LRD) control in CCRT group was $41 \%$ versus $50 \%$ for the RT group, such a finding was not statistically significant $(P=0.74)$. The 5 year OS was $70 \%$ with CCRT versus $43 \%$ with RT alone $(P=0.04)$ and $85 \%$ in patients attained disease control versus $55 \%$ in those developed disease recurrence $(P=0.01)$. The 5 year DFS was $46 \%$ versus $50 \%$ for CCRT versus RT alone $(P=0.27)$. Although more acute morbidities were observed in CCRT versus RT alone $(92$ vs $8 \%)$, the difference was marginally significant $(P=0.07)$. For chronic toxicities, more toxicities were associated with radiotherapy dose at 70 Gy than with dose $<70$ Gy but the difference also was marginally significant $(P=0.06)$

Conclusion: In spite of the small number of patients in our study, our results are in agreement with many other studies that support the concomitant approach in treating NPC. Weekly low dose cisplatin is easier to manage than the three weekly cisplatin schedules with more tolerable toxicities. Further randomized studies comparing both schedules are needed.

Key words: nasopharyngeal carcinoma, concomitant radiotherapy , weekly cisplatin

Corresponding Author: Ali Mohamed Ali_ E-mail: amali69eg@yahoo.com

\section{INTRODUCTION}

Nasopharyngeal carcinoma (NPC) is a common head and neck cancer. The incidence rate is higher in southern China and Southeast Asia in comparison with the Western countries. Management of nasopharyngeal carcinoma is one of the greatest clinical challenges. Appropriate detection is not easy because of its anatomical location. Radiotherapy is the standard treatment for nasopharyngeal carcinoma. Unfortunately, it can produce undesirable complications after treatment because of the location of the tumour at the base of skull, closely surrounded by and in close proximity to radiation dose-limiting organs, including the brain stem, spinal cord, pituitary-hypothalamic axis, temporal lobes, eyes, middle, inner ears, and parotid glands. A total dose of 70 Gy or above is needed for the gross tumour and 50-60 Gy for elective treatment of potential at risk sites ${ }^{1,2}$.

Although NPC is a radiosensitive tumor, the results of conventional radiotherapy (RT) techniques and fractionation are unsatisfactory for patients with 
advanced locoregional disease. Since the publication of the Intergroup 0099 study which showed that adding chemotherapy (CDDP $100 \mathrm{mg} / \mathrm{m} 2 \mathrm{D} \mathrm{1,} \mathrm{22,} \mathrm{43)}$ concurrently with RT followed by adjuvant chemotherapy (CDDP $80 \mathrm{mg} / \mathrm{m} 2$ and 5-Flourouracil $1000 \mathrm{mg} / \mathrm{m} 2$ on 96 hr) D 71, 99, 127 has improved survival outcome in stage III-IVB nasopharyngeal tumors 3 , it became a standard practice in treating locally advanced nasopharyngeal carcinoma.

Owing to the high rate of severe mucosal and bone marrow toxicities reported with this high dose of cisplatin and based on studies published since 1983 on the use of weekly low dose cisplatin concomitantly with radiotherapy, it was a standard in our department to treat locally advanced squamous cell carcinoma of the nasopharynx with chemoradiotherapy using concomitant low dose of cisplatin at $30-40 \mathrm{mg} / \mathrm{m}^{2}$.

In the present retrospective study on 32 patients of locally advanced nasopharyngeal carcinoma the primary end point was to determine the efficacy of concomitant radiochemotherapy using weekly cisplatin in terms of overall survival OS and disease free survival DFS while the secondary end point was to assess the toxicity profile associated with treatment by both modalities and factors associated with them.

\section{MATERIALS AND METHOD}

\section{Patients' characteristics:}

Medical records of adult patients with nasopharyngeal carcinoma treated in Sohag Faculty of Medicine and Sohag Cancer Institute, Sohag, Egypt between August 1999 and November 2012 by conventional 2-dimensional radiotherapy (2D) with or without chemotherapy were, retrospectively reviewed in this study. To be eligible for enrolment, patients should have locally advanced, non metastatic, pathologically proved diagnosis of squamous cell carcinoma of the nasopharynx, Pre-treatment evaluation included clinical examination, fibreoptic endoscopic examination of the upper aerodigestive tract, computerized tomography (CT) and/or magnetic resonance imaging (MRI) of the head and neck, chest $\mathrm{x}$ ray, complete blood count $(\mathrm{CBC})$, liver, renal function tests (LFTs, KFTs) and, dental assessment. Patients with history of previous treatment of cancer or having double malignancies should not be enrolled in the study. Performance status was assessed using the WHO scaling system.

\section{Disease's characteristics:}

We revised the tumors characteristics from the patients files and staged them according to the 6Th edition of TNM classification 2002. The disease should be measurable at the start of treatment. Disease response was assessed according to The Response Evaluation Criteria in Solid Tumour (RECIST). Complete response (CR) is considered when all target lesions disappear. Partial response (PR) when at least $30 \%$ decrease in the sum of the longest diameter of the target lesions and progressive disease (PD)when at least 20\% increase in the sum of the longest diameter of the target lesions or appearance of new lesions.

\section{Radiotherapy:}

The planned radiotherapy dose was ranging from 66 - 70 Gy to be delivered in conventional fractionation at 5 sessions per week from Saturday to Wednesday for 7 weeks. Planning for radiotherapy was done using conventional simulator and 2 dimensional (2D) planning system. Linear accelerator emitting photon beam at $6 \mathrm{MV}$ was used for irradiation of the primary and neck nodes up to the tolerance of the spinal cord while electron beam at $10 \mathrm{MeV}$ was used to complete the dose to the posterior neck nodes.

The patients underwent planning and irradiation in supine position with neck extension and head and shoulders being immobilized in thermoplastic masks fixed at 4 points.

All treatment plans were designed in accordance with CT/MRI images (pre-radiotherapy and during radiotherapy) and physical examination, including nasopharyngoscopic findings.

Treatment consisted of three fields, two lateral opposed fields (6 MV-photons) to the primary tumor and the cervical lymph nodes and one anterior field (6 MVphotons) to the supraclavicular lymph nodes.

The initial volume includes the tumour extension plus safety margin, nasopharynx, oropharynx and hypopharynx together with neck nodes on both sides from mastoid process to the supraclavicular region to a dose of $40 \mathrm{~Gy}$. The superior border usually $0.5 \mathrm{~cm}$ above the clinioid process, anteriorly, bisecting the maxillary antrum posteriorly covering the posterior neck chain leaving just a skin fold or open field in case of palpable posterior neck nodes and, inferiorly matching with the lower neck field at a level not cutting through a part of the disease. The lower neck field extends inferiorly to the inferior aspect of the medial end of the clavicle and laterally covering the medial $2 / 3$ of the clavicle.

Then phase two consisting of 10 Gy to the same volume after shielding the spinal cord and irradiating the posterior neck nodes with electron beam at $10 \mathrm{MeV}$.

Then the boost dose was from $16-20$ Gy to the nasopharynx and residual local/nodal disease. 


\section{Kasr-El-Aini Journal Of Clinical Oncology And Nuclear Medicine

Vol. 8 | No. 3-4 2012 \\ The impact of radiotherapy and concomitant weekly cisplatin}

The dose to the tumour and upper lateral neck fields was prescribed as midline dose while that for the lower neck field and the posterior neck chain was prescribed as given dose. Simulator check films were taken for verification of the field borders and positions of the blocks for the posterior brain fossa, oral cavity and, spinal cord. For tumors with intracranial extension, the field borders covered any tumor extension with safety margin $2 \mathrm{~cm}$ plus the above mentioned volumes.

During the course of radiotherapy, the patients underwent checks up for assessment of disease response and management of side effects.

\section{Chemotherapy:}

For patients receiving concomitant chemotherapy, CBC, KFTs and, LFTs were done before each cycle. Patients received weekly cisplatin, the dose was 30 $40 \mathrm{mg} / \mathrm{m} 2$ as an hour infusion in the outpatient hall at the start of every week of irradiation provided that the absolute neutrophil count $\geq 1,500 / 1$ and ? or, platelet count $\geq 100,000 / 1$ and, $24 \mathrm{~h}$ creatinine clearance $\geq 60 \mathrm{ml} /$ min or serum creatinine within the normal range.

The cisplatin dose was modified on a case-bycase basis according to the level of leucopenia and/or thrombocytopenia, the serum creatinine and/or creatinine clearance.

At the end of treatment, follow up was monthly in the first year and then every $3 \mathrm{~ms}$ in the second year then on longer intervals thereafter. In the follow up visits, evaluation done by means of clinical examination, naso endoscopy and CT or MRI if needed.

\section{Treatment toxicities:}

Treatment related morbidities were classified according to The Common Toxicity Criteria for Adverse Events version 3 (CTCAE, V3). Acute toxicities are considered when occur within 3 months from the end of treatment while, chronic ones were considered when morbidities last longer than that.

\section{Tumor recurrence:}

Disease recurrence was diagnosed both clinically and radiologically and defined as reappearance of the tumour or enlarged nodes, and/or distant metastases. Patients with persistent disease and those with recurrent disease after attaining CR were considered to be local failures

\section{Statistical analysis:}

Chi-square and Fisher exact test were used when appropriate to test the null hypothesis of no difference between proportions of the compared groups. MannWhitney test was used to compare between continuous variables in the compared groups. Direct logistic regression was done to assess the impact of different predictive factors on the occurrence of tumour response.

Disease free survival (DFS) was defined as the time between end of treatment and development of recurrence or distant metastasis after attaining CR, overall survival (OS) was defined as the time between diagnosis and death due to any cause. Both were calculated by the KaplanMeier method.

The non parametric log-rank test was used to test the null hypothesis of no differences in survival times between the studied groups. Statistical significance was assumed for a two tailed $\mathrm{P}$ value $<0.05$. Statistical analysis was done using SPSS version 15 .

\section{RESULTS}

Between August 1999 and November 2012 we identified 34 patients with non metastatic nasopharyngeal squamous cell carcinoma, Two patients had early T1/2 disease were excluded Thirty two patients having locally advanced disease were analyzed. Twenty seven patients were males while 5 were females ( $84 \%$ versus $16 \%)$. All patients treated by 2-dimensional radiotherapy (2D RT) with or withouit chemotherapy. Ages of the patients ranged from 25 to 82 years with a mean age 56.36 years \& Std. deviation 16 (Table1). Ten patients (31\%) were older than 65 year. No significant difference in the median age between males ( 56.27 years and females (56.88 years) with $P=0.94$. There was a significant association between history of smoking and sex, that all smokers had been males $(P=.005)$.

Patients reported lymph node enlargement in 5 cases $(16 \%)$, tinnitus in $5(16 \%)$, nasal obstruction in $4(12.5 \%)$, headache in $2(6 \%)$ nasal discharge in one case, mix of symptoms in $6(19 \%)$ and in $9(28 \%)$ cases, no initial symptoms were reported in the patients files. The most common pathological grade was grade 3 . No metastases were found at the start of treatment.

The patients are divided into 2 groups, one group ( 25 patients, $78 \%$ ) received concomitant chemo radiotherapy and the other 7 patients, $22 \%$. received only radiotherapy. A dose of 70 Gy was prescribed in 24 patients $(75 \%)$ while 6 patients (19\%) received doses from 66 to $70 \mathrm{~Gy}$ and one received 54 Gy (3\%) and no data on dose was reported in one patient. Duration of radiotherapy ranged from 6 - 10 weeks (mean;7.4 wk \& std;1.04).

Chemotherapy in the form of weekly cisplatin was given in $25(78 \%)$ patients. Two patients received only one week chemotherapy due to patient refusal, three patients received 2 weeks and five received only 3 weeks due to severe mucositis, four patients received 7 weeks, 
one received 5 and another one received 6 weeks. In nine patients, no definite data regarding the number of chemotherapy cycles.

\section{Treatment related morbidities:}

Side effects reported by the patients (Table 2) included acute mucositis, nausea, vomiting, altered renal functions, dysphagia, xerostomia, altered taste and cytopenia. While long term morbidities included; trismus, teeth necrosis, temporal necrosis, chronic mastoiditis, and brachial plexopathy.

Mild to moderate acute toxicities e,g ; acute mucositis, dysphagia altered taste and, xerostomia were associated with the age of the patients $(P=0.005)$. Severe acute toxicities were more common in patients received concomitant chemo-radiotherapy but the difference was marginally significant $(0.07)$. For chronic toxicities, more toxicities were noticed in males than females $(P=0.06)$ and with radiotherapy dose at 70 Gy compared to doses less than 70 Gy $(P=0.06)$. No other significant associations were found between treatment related toxicities and other possible risk factors as seen in Table (3).

\section{Treatment response, recurrence and survival:}

The time between the end of treatment and the first follow up ranged from 1-8 m (mean: $2.36 \mathrm{~m}$ ).

After treatment either with radiotherapy alone or with concomitant chemoradiotherapy, complete remission (CR) was reported in 21 patients $(68 \%)$, partial remission (PR) in 7 patients $(22 \%)$ and, stable disease (SD) in 3 patients $(10 \%)$ while in one patient, no data was present. Table (4) summarizes the factors affected the response to treatment and it is obvious from that table that only the age $\leq 65$ years and performance status at 0 were associated with higher incidence of $\mathrm{CR}(P=0.001$ and 0.008 , respectively).

During follow up, 11 out of the 21 patients (52\%) who attained CR developed locoregional recurrences (LRR) ,9 in the CCRT and 2 in the RT group, for which they received either cisplatin / 5 FU or carboplatin/ 5 FU while, 10 patients (48\%) maintained locoregional control. For distant metastasis, 3 in the CCRT and 1 in the RT group were found. The time to recurrence ranged from $7-150 \mathrm{~ms}$ with a mean at $71.25 \mathrm{~ms}(\mathrm{sdv}$ $49.33 \mathrm{~m})$.

As shown in Table (5), 10 from 17 patients (55\%) in the CCRT group (whose data were available) developed loco regional distant (LRD) failure while 7 (39\%) achieved locoregional distant tumor control and in one patient $(0.5 \%)$ no data was available. In the RT alone group, 2 patients developed LRD failure while 2 had LRD tumor control as seen in Table (5).
Although more recurrences were noticed with advanced stage, undifferentiated tumours, concomitant radio chemotherapy, radiation dose $70 \mathrm{~Gy}$, age younger than $65 \mathrm{yrs}$ and, history of smoking, none of these studied risk factors were significantly associated with disease failure as shown in Table (5).

During follow up, 16 patients died (50\%). For the whole group, the 5 year DFS was $52 \%$ (Figure1), while the 5 year OS was $65 \%$ (Figure 2). No significant differences between subgroups of risk factors were found associated with better DFS as shown in Table (6), but for OS, predictive factors of better OS were absence of loco regional/distant relapse $(P=0.01)$ and, concomitant chemo radiotherapy $(P=0.04)$ as shown in (Figure 3 and 4 ) respectively. Patients age $\leq 65$ year was also associated with marginally better OS than was age $>65$ year as shown in Table (6).

The median OS for radiotherapy alone group was 10.7 months versus not reached for the concomitant radio chemotherapy group. Table (7) shows the treatment outcome in CCRT and radiotherapy groups.

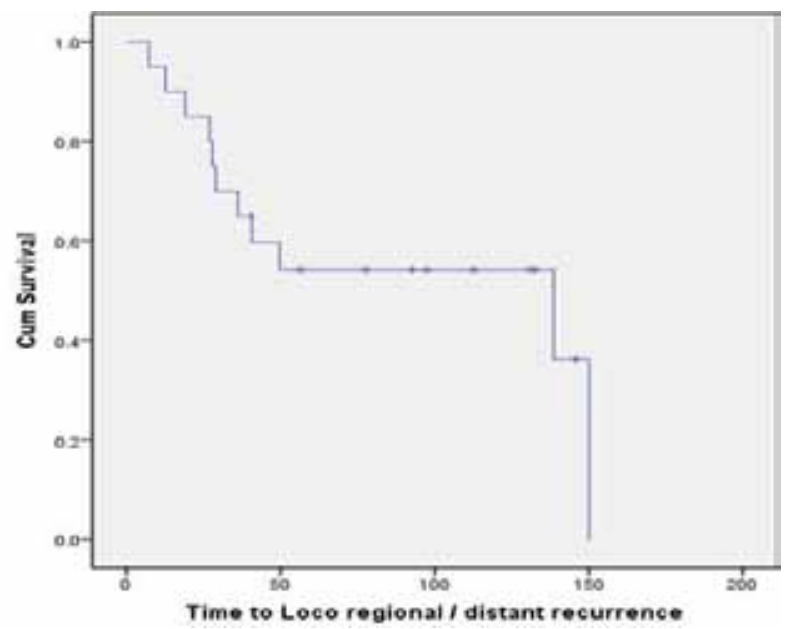

Figure 1: Impact of disease recurrnce on OS.

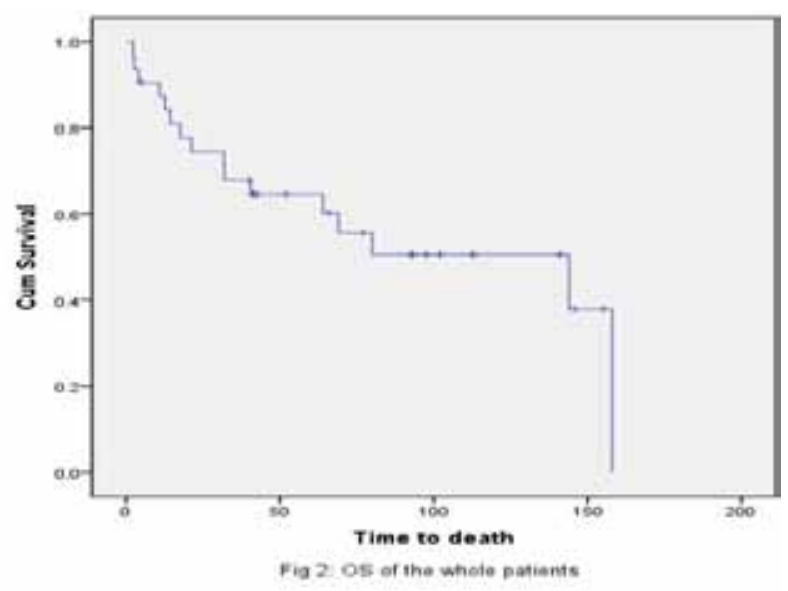

Figure 2: OS of the whole patients. 


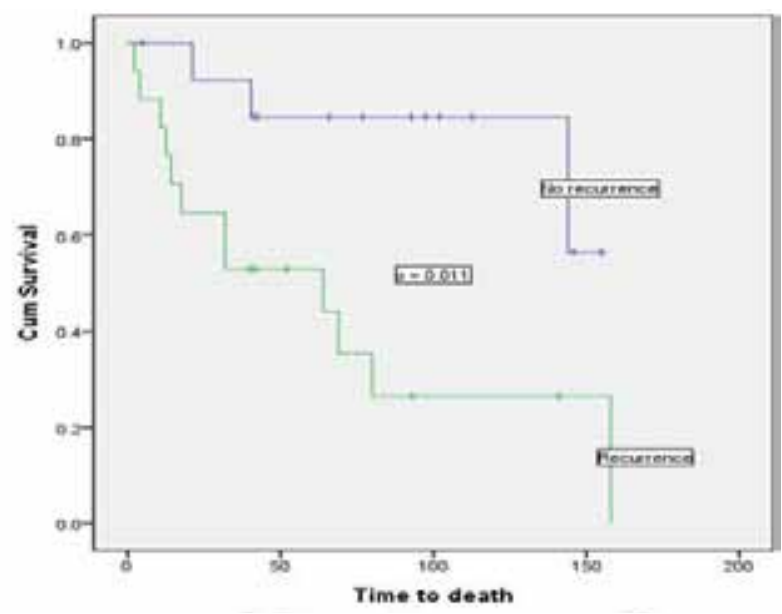

Figure 3: Impact of disease recurrence on OS

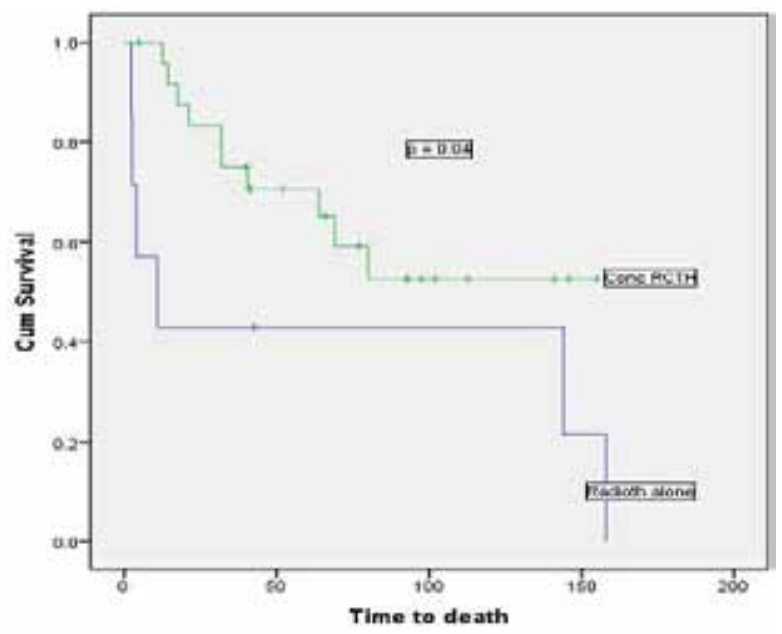

Figure 3: Impact of concomitant radio chemotherapy on OS.

Table 1: Patients and disease characteristics.

\begin{tabular}{|c|c|c|c|c|}
\hline Patient \& disease characteristics & Radio chemotherapy n (\%) & Radiotherapy alone n (\%) & Missed & P value \\
\hline Number & $25 / 32(78 \%)$ & $7 / 32(22 \%)$ & 0 & \\
\hline \multicolumn{5}{|l|}{ Gender } \\
\hline Male & $21 / 25(84 \%)$ & $6 / 7(86 \%)$ & \multirow{2}{*}{0} & \multirow{2}{*}{0.912} \\
\hline Female & $4 / 25(16 \%)$ & $1 / 7(14 \%)$ & & \\
\hline Mean age & 53.6 yr std: 15 & 66 yr std: 17 & -- & $\underline{0.068}$ \\
\hline \multicolumn{5}{|l|}{ Performance status (WHO) } \\
\hline 0 & $6 / 11(54.5 \%)$ & $2 / 4(50 \%)$ & \multirow{2}{*}{17} & \multirow{2}{*}{0.876} \\
\hline 1 & $5 / 11(45.5 \%)$ & $2 / 4(50 \%)$ & & \\
\hline Smoking & $5 / 6(83.3 \%)$ & $2 / 2(100 \%)$ & 25 & 0.537 \\
\hline \multicolumn{5}{|l|}{ Stage } \\
\hline $\mathrm{T} 3 / 4+/-\mathrm{N}+$ & $24 / 25(96 \%)$ & $5 / 7(71 \%)$ & 3 & 0.320 \\
\hline \multicolumn{5}{|l|}{ Pathological Grade } \\
\hline Undifferentiated & $10 / 11(91 \%)$ & $2 / 2(100 \%)$ & \multirow{2}{*}{19} & \multirow{2}{*}{0.657} \\
\hline Moderately differentiated & $1 / 11(9 \%)$ & $0 / 2(0 \%)$ & & \\
\hline Median follow up & $8 \mathrm{~m}(6-10 \mathrm{~m})$ & $8 \mathrm{~m} \mathrm{(4-8} \mathrm{m)}$ & -- & 0.200 \\
\hline \multicolumn{5}{|l|}{ Radiation dose } \\
\hline 70 Gy & $19(76)$ & $5(83)$ & \multirow{2}{*}{31} & \multirow{2}{*}{0.70} \\
\hline$<70 \mathrm{~Gy}$ & $6(24)$ & $1(17)$ & & \\
\hline Radiotherapy duration & Mean: 7.60 (sdn.0.76) & Mean: 6.86 (sdn.1.67) & -- & 0.59 \\
\hline
\end{tabular}

Table 2: Frequency of treatment related morbidities.

\begin{tabular}{lcc}
\hline Side effects & Radio chemo n(\%) & Radiotherapy alone n(\%) \\
\hline Acute nausea and vomiting & $15(88)$ & $2(12)$ \\
Acute mucositis grade 1/2 & $4(80)$ & $1(20)$ \\
Acute mucositis grade 3/4 & $11(92)$ & $1(8)$ \\
Acute mild renal dysfunction & $8(32)$ & 0 \\
Acute dysphagia grade 3/4 & $5(83)$ & $1(17)$ \\
Xerostomia & $5(83)$ & $1(17)$ \\
Altered taste sensation & $3(75)$ & 0 \\
Cytopenia grade 3/4 & $2(100)$ & 0 \\
Chronic xerostomia & $5(100)$ & $1(20)$ \\
Trismus & $4(80)$ & 0 \\
Teeth necrosis & $4(100)$ & 0 \\
Temporal necrosis & $1(100)$ & 0 \\
Brachial plexopathy & $1(100)$ & $1(50)$ \\
Mastoiditis & $1(50)$ & \\
\hline
\end{tabular}


Kasr-El-Aini Journal Of Clinical Oncology And Nuclear Medicine

$$
\text { Vol. } 8 \text { | No. 3-4 } 2012
$$

Ali Mohammed Ali and Ashraf M Elyamany

Table 3: Correlations between acute and chronic treatments related side effects and potential risk factors.

\begin{tabular}{lcc}
\hline Predictive factor & Acute toxicities G 2 \% (P value) & $\begin{array}{c}\text { Acute toxicities G 3/4 \% (P value) } \\
\text { Chronic toxicities G3/4 } \\
\%(P \text { value })\end{array}$ \\
\hline Age: $=<65$ vs $>65$ y & $83 \%$ vs $17 \%(0.005)$ & $69 \%$ vs $31(0.79)$ \\
\hline Gender: male vs female & $83 \%$ vs $17 \%(0.82)$ & $77 \%$ vs $23 \%(0.41)$ \\
\hline Smoking: yes vs no & $100 \%$ vs $0 \%(0.49)$ & $100 \%$ vs $27 \%(1.00)$ \\
\hline Concomitant radiochemo vs radio alone & $78 \%$ vs $22 \%(0.40)$ & $64 \%$ vs $36 \%(0.06)$ \\
\hline Radiation: dose: 70 vs $<70$ Gy & $71 \%$ vs $29 \%(0.59)$ & $92 \%$ vs $8 \%(0.07)$ \\
\hline
\end{tabular}

Table 4: Response after treatment and predictive factors.

\begin{tabular}{|c|c|c|c|c|}
\hline \multirow{2}{*}{ Variable } & \multicolumn{3}{|c|}{ Response following treatment } & \multirow{2}{*}{$P$ value } \\
\hline & Complete response & Partial/stable/progressive disease & missed & \\
\hline \multicolumn{5}{|l|}{ Age } \\
\hline$\leq 65$ year & 19 & 3 & 1 & \multirow{2}{*}{0.001} \\
\hline$>65$ year & 2 & 7 & & \\
\hline \multicolumn{5}{|l|}{ Sex } \\
\hline Male & 17 & 9 & 1 & \multirow{2}{*}{0.522} \\
\hline female & 4 & 1 & & \\
\hline \multicolumn{5}{|l|}{ Performance status } \\
\hline 0 & 7 & 1 & 18 & \multirow[b]{2}{*}{0.008} \\
\hline$\geq 1$ & 1 & 5 & & \\
\hline \multicolumn{5}{|l|}{ Smoking history } \\
\hline Yes & 3 & 4 & \multirow{2}{*}{24} & \multirow{2}{*}{0.285} \\
\hline no & 1 & 0 & & \\
\hline \multicolumn{5}{|l|}{ Grade } \\
\hline Moderately differentiated & 1 & 0 & & \multirow{2}{*}{0.546} \\
\hline Undifferentiated & 8 & 3 & 20 & \\
\hline \multicolumn{5}{|l|}{ Treatment } \\
\hline CCRT & 18 & 7 & 1 & \multirow{2}{*}{0.301} \\
\hline RT alone & 3 & 3 & & \\
\hline \multicolumn{5}{|l|}{ Radiation dose } \\
\hline 70 Gy & 18 & 6 & 2 & \multirow{2}{*}{0.232} \\
\hline$<70 \mathrm{~Gy}$ & 3 & 3 & & \\
\hline
\end{tabular}

Table 5 Loco regional recurrences and possible predictive factors.

\begin{tabular}{|c|c|c|c|c|c|}
\hline \multirow{2}{*}{ Risk factors } & \multicolumn{4}{|c|}{ Loco-regional/distant recurrences } & \multirow{2}{*}{$P$ value } \\
\hline & Yes & No & Missed & total & \\
\hline \multicolumn{6}{|l|}{ Stage } \\
\hline $\mathrm{T} 3 / 4+/-\mathrm{N}+$ & $10(48 \%)$ & $9(43 \%)$ & $2(9 \%)$ & 21 & 0.93 \\
\hline \multicolumn{6}{|l|}{ Treatment modality } \\
\hline Conc chemoradiotherapy & $10(59 \%)$ & $7(41 \%)$ & & & \\
\hline Radiotherapy alone & $2(50 \%)$ & $2(50 \%)$ & 0 & 21 & 0.74 \\
\hline Total & $12(57 \%)$ & $9(43 \%)$ & & & \\
\hline \multicolumn{6}{|l|}{ Dose Radio } \\
\hline 70 Gy & $11(92 \%)$ & $7(78 \%)$ & & 21 & \\
\hline$<70 \mathrm{~Gy}$ & $1(8 \%)$ & $2(22 \%)$ & 0 & & 0.36 \\
\hline Total & $12(100 \%)$ & $9(100 \%)$ & & & \\
\hline \multicolumn{6}{|l|}{ Grade } \\
\hline Moderately diffentiated & $0(0 \%)$ & $1(33 \%)$ & & & \\
\hline Undifferentiated & $6(100 \%)$ & $2(67 \%)$ & 12 & 21 & 0.13 \\
\hline Total & 6 & 3 & & & \\
\hline \multicolumn{6}{|l|}{ Age } \\
\hline$<=65$ & $11(92 \%)$ & $8(89 \%)$ & 0 & 19 & \\
\hline$>65$ & $1(8 \%)$ & $1(11 \%)$ & 0 & 2 & 0.83 \\
\hline Total & 12 & 9 & & 21 & \\
\hline \multicolumn{6}{|l|}{ Smoking history } \\
\hline Smoker & $1(100 \%)$ & $2(67 \%)$ & & & \\
\hline Non smoker & 0 & $1(33 \%)$ & 17 & 21 & 0.50 \\
\hline Total & 1 & 3 & & & \\
\hline
\end{tabular}


Table 6: Survival times and predictive factors.

\begin{tabular}{lcc}
\hline Predictive factor & 5 Year OS (P value) & 5 Year DFS $(\boldsymbol{P}$ value $)$ \\
\hline Age: $=<65$ vs $>65 \mathrm{yr}$ & $72 \%$ vs $45 \%(0.06)$ & $55 \%$ vs $32 \%(0.37)$ \\
\hline Gender: males vs females & $62 \%$ vs $80 \%(0.48)$ & $50 \%$ vs $68 \%(0.40)$ \\
\hline Smoking: yes vs no & $50 \%$ vs $100 \%(0.44)$ & $50 \%$ vs $100 \%(0.44)$ \\
\hline Grade: undifferentiated vs moderately differentiated grade & $75 \%$ vs NR $(0.30)$ & $38 \%$ vs NR $(0.51)$ \\
\hline Radiotherapy dose: 70 vs $<70$ Gray & $72 \%$ vs $52 \%(0.59)$ & $48 \%$ vs $100 \%(0.19)$ \\
\hline Concomitant Chemotherapy: yes vs no & $70 \%$ vs $43 \%(0.04)$ & $46 \%$ vs $50 \%(0.27)$ \\
\hline Loco regional / distant recurrence : yes vs no & $55 \%$ vs $85 \%(0.01)$ & Not applicable \\
\hline
\end{tabular}

Table 7: Treatment outcome of the patients groups.

\begin{tabular}{lccc}
\hline Treatment outcome & Radio chemotherapy $\mathbf{n}(\%)$ & Radiotherapy alone n(\%) & $\boldsymbol{P}$ value \\
\hline Response & $17(68)$ & $4(57)$ & \\
CR & $5(20)$ & $2(28.5)$ & 0.11 \\
PR & $2(8)$ & $1(14)$ & \\
SD & $1(4)$ & 0 & 0.43 \\
Missed & & & \\
\hline Recurrence & $6(50)$ & $2(67)$ & 0.44 \\
Local & $3(25)$ & 0 & 0.04 \\
Nodal & $3(25)$ & $4(33)$ & 0.27 \\
Distant & $70 \%$ & $50 \%$ & \\
\hline 5 year OS & $46 \%$ & & \\
\hline 5 year DFS & & & \\
\hline
\end{tabular}

Table 8: Trials on radiotherapy concomitant with weekly cisplatin.

\begin{tabular}{|c|c|c|c|c|c|c|c|}
\hline \multirow{2}{*}{ Author } & \multirow{2}{*}{$\begin{array}{l}\text { No. of patients in } \\
\text { the study }\end{array}$} & \multirow{2}{*}{ Dose of RT } & \multirow{2}{*}{$\begin{array}{c}\text { Dose of } \\
\text { Cisplatin }\end{array}$} & \multirow{2}{*}{$\begin{array}{l}\text { Follow up } \\
\text { duration }\end{array}$} & \multicolumn{3}{|c|}{ Outcome } \\
\hline & & & & & OS & TTP & LRC \\
\hline Colombo $\mathrm{A}^{14}$ & 19 head and neck & $70 \mathrm{~Gy}$ & $20 \mathrm{mg} / \mathrm{m}^{2}$ & 24 months & & $\begin{array}{l}24 \text { months } \\
\text { DFS: } 75 \%\end{array}$ & $57 \%$ \\
\hline Bachaud JM ${ }^{15}$ & 83 head and neck & 70 Gy & $50 \mathrm{mg} / \mathrm{m}^{2}$ & & $\begin{array}{l}\text { At } 2 \text { years: } \\
65 \text { vs } 41 \%\end{array}$ & & $\begin{array}{l}79 \text { vs } 59 \% \text { for } \\
\text { CCRT }\end{array}$ \\
\hline Glaser $\mathrm{MG}^{16}$ & 36 & 70 Gy & $40 \mathrm{mg} / \mathrm{m}^{2}$ & & & $\begin{array}{l}\text { At } 2 \text { years, } \\
\text { DFS: } 52 \%\end{array}$ & \\
\hline Bachaud JM ${ }^{17}$ & 83 head and neck & 70 Gy & $50 \mathrm{mg} / \mathrm{m}^{2}$ & & & & $\begin{array}{l}77 \text { vs } 59 \% \text { for } \\
\text { CCRT }\end{array}$ \\
\hline Gupta $T^{18}$ & 264 head and neck & 66 - 70 Gy & $30 \mathrm{mg} / \mathrm{m}^{2}$ & 19 months & & $\begin{array}{c}5 \text { years DFS: } \\
43 \%\end{array}$ & $\begin{array}{c}\text { At } 5 \\
\text { years: } 46 \%\end{array}$ \\
\hline Steinmann $\mathrm{D}^{19}$ & 103 head and neck & $70 \mathrm{~Gy}$ & $40 \mathrm{mg} / \mathrm{m}^{2}$ & 65 months & $\begin{array}{c}\text { At } 18 \\
\text { months: } \\
83.3 \% \text { vs } \\
72.1 \% \\
\end{array}$ & & $\begin{array}{c}\text { At } 18 \text { months } \\
66.7 \% \text { vs } \\
78.7 \% \text { for } \\
\text { CCRT } \\
\end{array}$ \\
\hline Sharma A ${ }^{20}$ & 153 head and neck & 70 Gy & $40 \mathrm{mg} / \mathrm{m}^{2}$ & 24 months & $\begin{array}{l}\text { At } 3 \text { Years: } \\
62 \text { vs } 42 \% \\
\text { for CCRT }\end{array}$ & & \\
\hline Watkins JM ${ }^{21}$ & 96 head and neck & $70 \mathrm{~Gy}$ & $30 \mathrm{mg} / \mathrm{m}^{2}$ & 40 months & $\begin{array}{l}\text { At } 4 \text { Years: } \\
58 \%\end{array}$ & $\begin{array}{l}\text { At } 4 \text { years } \\
\text { DFS: } 58 \%\end{array}$ & \\
\hline Quon $\mathrm{H}^{22}$ & 371 & $70 \mathrm{~Gy}$ & $20 \mathrm{mg} / \mathrm{m}^{2}$ & 62 months & & $\begin{array}{l}\text { Median : } 7.2 \\
\text { vs } 6.5 \text { months } \\
\text { for CCRT }\end{array}$ & \\
\hline Homma $\mathrm{A}^{23}$ & 51 head and neck & $70 \mathrm{~Gy}$ & $40 \mathrm{mg} / \mathrm{m}^{2}$ & 24 months & $\begin{array}{c}\text { At } 2 \text { Years : } \\
93.7 \%\end{array}$ & $\begin{array}{c}\text { At } 2 \text { Years : } \\
88 \%\end{array}$ & \\
\hline Pala M ${ }^{24}$ & 148 & 70 Gy & $40 \mathrm{mg} / \mathrm{m}^{2}$ & 40 months & $\begin{array}{c}\text { At } 3 \\
\text { Years:34\% }\end{array}$ & & $60 \%$ \\
\hline
\end{tabular}




\section{DISCUSSION}

The result with radiotherapy alone in patients with locally advanced nasopharyngeal carcinoma (NPC) was disappointing. Encouraging results have been reported with the use of concurrent chemo-radiotherapy in patients with locally advanced squamous cell carcinoma of the head and neck. In the earlier randomized studies, cisplatin-based CCRT has been demonstrated to have higher efficacy than RT alone in patients with locally advanced NPC [4, 5, 6]. Concomitant chemotherapy during RT has been shown to improve local disease control by radiosensitizing effect and also found to significantly reduce distant metastasis ${ }^{7}$.

The enhanced cell killing observed when platinum analouges administered prior to or following radiation is believed to be mediated through a variety of mechanisms, including but not limited to enhanced formation of toxic platinum intermediates in the presence of radiation induced free radicals, a radiationinduced increase in cellular platinum uptake, inhibition of DNA repair, and cell cycle arrest ${ }^{8}$.

In $1998 \mathrm{Al}$ Sarraf and colleagues published the results of the Intergroup 0099 study which showed that adding chemotherapy (CDDP $100 \mathrm{mg} / \mathrm{m}^{2} \mathrm{D} \mathrm{1,} \mathrm{22,} \mathrm{43)}$ concurrently with RT followed by adjuvant chemotherapy (CDDP $80 \mathrm{mg} / \mathrm{m}^{2}$ and 5-Flourouracil $1000 \mathrm{mg} / \mathrm{m}^{2}$ on $96 \mathrm{hr}$ ) D 71,99,127 has improved survival outcome in stage III-IVB nasopharyngeal tumors ${ }^{3}$ and since then, it became a standard practice in treating locally advanced nasopharyngeal carcinoma and, such a finding was later confirmed in many randomized studies ${ }^{9,10,11}$.

A large meta analysis conducted by Baujat B, and colleagues and included 8 randomised trials with 1753 patients of locally advanced nasopharyngeal carcinoma showed that after a median follow up period of six years the pooled hazard ratio of death was 0.82 ( 0.71 to 0.95 ; $P=0.006)$ corresponding to an absolute survival benefit of $6 \%$ at five years from chemo-radiotherapy (from $56 \%$ to $62 \%$ ). Such a benefit was more associated with concomitant rather than with adjuvant chemotherapy ${ }^{7}$.

Another large study conducted by Chen $\mathrm{Y}$ and colleagues and included 316 patients with nasopharyngeal carcinoma found that the 2-year overall survival rate, failure-free survival rate, distant failure-free survival rate, and loco-regional failure-free survival rate for the CRT and RT groups were $89.8 \%$ vs. $79.7 \%(P=0.003)$, $84.6 \%$ vs. $72.5 \%(P=0.001), 86.5 \%$ vs. $78.7 \%(P=$ $0.024)$, and $98.0 \%$ vs. $91.9 \%(P=0.007)$, respectively ${ }^{12}$.

However, in contrast to these results, different results were also reported. Anne W and colleagues in their study on 348 patients with non metastatic nasopharyngeal carcinoma found no significant difference in 5 year OS between patients treated with chemo-radiotherapy and those received radiotherapy alone (CRT vs RT: $68 \%$ vs $64 \% ; P=0.22)$ in spite of difference in 5-year progressionfree survival in favor of CRT $(62 \% \text { vs } 53 \% ; P=.035)^{13}$.

Owing to the high rate of severe acute mucosal and bone marrow toxicities reported with concurrent chemo radiotherapy using high dose of cisplatin and based on studies published since 1983 on the use of weekly low dose cisplatin concomitantly with radiotherapy as shown in table 8 it was a practice in our department to treat squamous cell carcinoma of the nasopharynx with chemoradiotherapy using concomitant low dose of cisplatin at $30-40 \mathrm{mg} / \mathrm{m}^{2}$. In this retrospective study of 32 patients, 25 received weekly cisplatin concomitantly with radiotherapy. There was a trend to spare chemotherapy to relatively young patients as shown in Table (1) where the mean age of the patients in the chemoradiotherapy arm was marginally significantly younger than that in the radiotherapy alone group $(P=0.068)$. Such a finding may explain why patients $<65$ year developed more acute toxicities than older ones (83 vs $17 \%, P=0.005$ ) as seen in Table (3).

When analyzing the predictive factors for the development of treatment related toxicities, although the acute toxicities were -as expected- more associated with CCRT than with radiotherapy alone $(92 \% \mathrm{vs} 8 \%, P 0.06)$, the more importantly chronic morbidities were not (91 vs $9 \%, P=0.20)$. The later were more correlated with radiation dose at 70 versus $<70$ Gy (64 vs $36 \%, P=0.06$ ) and male rather than female gender ( 64 vs $36 \%, P=0.06$ ). Such an association between chronic toxicities and radiation dose is expected when conventional rather than conformal radiotherapy is used. A fact that highlights the importance and need of acquiring the new sophisticated techniques such as 3-D RT and intensity modulated radiotherapy (IMRT). The other factor associated with chronic toxicities was the male gender, a finding that can be attributed to the significant association between smoking and male gender ( $100 \%$ versus $0 \%, P=0.005$ ) which was the only difference between males and females in this study.

As regards the OS and DFS, it is obvious from Table (6) that the only predictive factors associated with better 5 year OS were CCRT and freedom from disease recurrences. The figures obtained in our study agree to much extent with those reported in other trials that mentioned in Table (8).

Having a look on Table (8). reveals that, the OS associated with concomitant weekly cisplatin ranged from $34 \%$ at 3 years reported by Pala $\mathrm{M}^{24}$ to $93.7 \%$ at 2 years reported by Homma $\mathrm{A}^{23}$ while the DFS ranged from $43 \%$ at 5 year reported by Gupta $\mathrm{T}^{17}$ to $88 \%$ at $2 \mathrm{yr}$ 
reported by Homma $\mathrm{A}^{23}$. In our study, the 5 year OS for weekly cisplatin was $70 \%$ and the 5 yr DFS was $46 \%$. On the level of rate of disease control, our result of $41 \%$ is lower than these reported by others and ranged from $60 \%$ reported by Pala $\mathrm{M}^{24}$ to $79 \%$ reported by Bachaud $\mathrm{JM}^{15}$.

\section{CONCLUSION}

Concomitant chemo radiotherapy at weekly low dose of cisplatin adds benefit to the overall survival of patients with locally advanced NPC but at the expense of acute treatment related toxicities and advanced techniques of radiotherapy are required to ameliorate the incidence of chronic toxicities

\section{REFERENCES}

1. Lee AW, Lau WH, Tung SY, Chua DT, Chappell R, Xu L, et al. Preliminary results of a randomized study on therapeutic gain by concurrent chemotherapy for regionally-advanced nasopharyngeal carcinoma: NPC9901 Trial by the Hong Kong Nasopharyngeal Cancer Study Group. J.Clin.Oncol. 2005;6966(6975):23-8.

2. Lee AW, Tung SY, Chua DT, Ngan RK, Chappell R, Tung R, et al. Randomized trial of radiotherapy plus concurrent-adjuvant chemotherapy vs radiotherapy alone for regionally advanced nasopharyngeal carcinoma. J.Natl.Cancer Inst. 2010;102(15):1188-98.

3. Al-Sarraf M, LeBlanc M, Giri PG, Fu KK, Cooper J, Vuong $\mathrm{T}$, et al. Chemoradiotherapy versus radiotherapy in patients with advanced nasopharyngeal cancer: Phase III randomized Intergroup study 0099. J.Clin.Oncol. 1998;16(4):1310-7.

4. Sesterhenn AM, Teymoortash A, Folz BJ, Werner JA. Head and neck cancer in the elderly: A cohort study in 40 patients. Acta Oncol. 2005;44(1):59-64.

5. Derks W, de Leeuw RJ, Hordijk GJ. Elderly patients with head and neck cancer: The influence of comorbidity on choice of therapy, complication rate and survival. Curr. Opin.Otolaryngol.Head Neck Surg. 2005;13(2):92-6.

6. Pignon T, Horiot JC, Van den Bogaert W, Van Glabbeke $\mathrm{M}$, Scalliet P. No age limit for radical radiotherapy in head and neck tumours. Eur.J.Cancer 1996;32A(12):2075-81.

7. Baujat B, Audry H, Bourhis J, Chan AT, Onat H, Chua DT, et al. Chemotherapy as an adjunct to radiotherapy in locally advanced nasopharyngeal carcinoma. Cochrane Database Syst.Rev. 2006(4):CD004329.

8. Amorino GP, Freeman ML, Carbone DP, Lebwohl DE, Choy H. Radiopotentiation by the oral platinum agent, JM216: Role of repair inhibition. Int.J.Radiat.Oncol.Biol. Phys. 1999;44(2):399-405.

9. Park KH, Kim JS, Park Y, Seo HY, Park YJ, Choi IK, et al. Concurrent chemoradiation followed by adjuvant chemotherapy in patients with locoregionally advanced nasopharyngeal carcinoma in Korea. Cancer Chemother. Pharmacol. 2010;66(4):643-51.
10. Lin JC, Jan JS, Hsu CY, Liang WM, Jiang RS, Wang WY. Phase III study of concurrent chemoradiotherapy versus radiotherapy alone for advanced nasopharyngeal carcinoma: Positive effect on overall and progression-free survival. J.Clin.Oncol. 2003;21(4):631-7.

11. Chan AT, Leung SF, Ngan RK, Teo PM, Lau WH, Kwan WH, et al. Overall survival after concurrent cisplatin-radiotherapy compared with radiotherapy alone in locoregionally advanced nasopharyngeal carcinoma. J.Natl.Cancer Inst. 2005;97(7):536-9.

12. Chen Y, Liu MZ, Liang SB, Zong JF, Mao YP, Tang LL, et al. Preliminary results of a prospective randomized trial comparing concurrent chemoradiotherapy plus adjuvant chemotherapy with radiotherapy alone in patients with locoregionally advanced nasopharyngeal carcinoma in endemic regions of china. Int.J.Radiat.Oncol.Biol.Phys. 2008;71(5):1356-64.

13. Colombo A, Crispino S, Barni S, Paolorossi F, Frigerio F, Tancini G, et al. [Concomitant therapy with cisplatin and radiotherapy in locally advanced tumors of the cervicofacial area]. Radiol.Med. 1987;74(4):334-7.

14. Bachaud JM, David JM, Boussin G, Daly N. Combined postoperative radiotherapy and weekly cisplatin infusion for locally advanced squamous cell carcinoma of the head and neck: preliminary report of a randomized trial. Int.J.Radiat.Oncol.Biol.Phys. 1991;20(2):243-6.

15. Glaser MG, Leslie MD, O'Reilly SM, Cheesman AD, Newlands ES. Weekly cisplatinum concomitant with radical radiotherapy in the treatment of advanced head and neck cancer. Clin.Oncol. 1993;5(5):286-9.

16. Bachaud JM, Cohen-Jonathan E, Alzieu C, David JM, Serrano E, Daly-Schveitzer N. Combined postoperative radiotherapy and weekly cisplatin infusion for locally advanced head and neck carcinoma: Final report of a randomized trial. Int.J.Radiat.Oncol.Biol.Phys. 1996;36(5):999-1004.

17. Gupta T, Agarwal JP, Ghosh-Laskar S, Parikh PM, D'Cruz AK, Dinshaw KA. Radical radiotherapy with concurrent weekly cisplatin in loco-regionally advanced squamous cell carcinoma of the head and neck: A single-institution experience. Head Neck Oncol. 2009;1:17.

18. Steinmann D, Cerny B, Karstens JH, Bremer M. Chemoradiotherapy with weekly cisplatin $40 \mathrm{mg} / \mathrm{m}^{2}$ in 103 head-and-neck cancer patients: a cumulative doseeffect analysis. Strahlenther.Onkol. 2009;185(10):682-8.

19. Sharma A, Mohanti BK, Thakar A, Bahadur S, Bhasker S. Concomitant chemoradiation versus radical radiotherapy in advanced squamous cell carcinoma of oropharynx and nasopharynx using weekly cisplatin: A phase II randomized trial. Ann.Oncol. 2010;21(11):2272-7.

20. Watkins JM, Zauls AJ, Wahlquist AH, Shirai K, GarrettMayer E, Gillespie MB, et al. Low-dose weekly platinumbased chemoradiation for advanced head and neck cancer. Laryngoscope 2010;120(2):236-42. 
21. Quon H, Leong T, Haselow R, Leipzig B, Cooper J, Forastiere A. Phase III study of radiation therapy with or without cis-platinum in patients with unresectable squamous or undifferentiated carcinoma of the head and neck: An intergroup trial of the Eastern Cooperative Oncology Group (E2382). Int.J.Radiat.Oncol.Biol. Phys. 2011;81(3):719-25.
22. Homma A, Inamura N, Oridate N, Suzuki S, Hatakeyama $\mathrm{H}$, Mizumachi T, et al. Concomitant weekly cisplatin and radiotherapy for head and neck cancer. Jpn.JClin.Oncol. 2011;41(8):980-6.

23. Pala M, Odrazka K, Holeckova P, Vitek P, Kubes J, Dvorak J, et al. Definitive radiochemotherapy with weekly cisplatin in patients with head and neck cancer; single institution outcome analysis. J.BUON. 2012;17(3):471-7. 